\title{
Performing Sensitive Clinical Examinations During Urological Telemedicine Visits: How to Avoid Pitfalls?
}

\author{
Chaitya Desai (1D' \\ Ian Pearce ${ }^{2}$ \\ Vaibhav Modgil ${ }^{2}$ \\ 'University Hospitals Birmingham NHS \\ Foundation Trust, Birmingham, UK; \\ ${ }^{2}$ Manchester Andrology Centre, \\ Manchester University NHS Foundation \\ Trust, Manchester, UK
}

Background and Aims: The impact of coronavirus disease 2019 presented an unprecedented challenge to urological service globally. In many countries, outpatient clinics were cancelled, and the use of telemedicine visits was increased. For urological complaints, the need to perform a sensitive clinical examination via telemedicine posed an unfamiliar environment. Our aim is to explore the clinical and ethical factors involved in performing remote sensitive clinical examinations.

Methods: A comprehensive review of literature and guidance from various medical bodies internationally was conducted using suitable keywords on the search engines of PubMed, SCOPUS, Google Scholar, and Research Gate in the first week of March 2021 including "COVID-19," "telemedicine," "urology," and "sensitive examinations."

Results: Telemedicine reduced unnecessary visits to medical facilities and was useful for reducing the risk of transmission during the COVID-19 pandemic. We propose that in order to perform a sensitive clinical examination via telemedicine, the following four steps must be considered: assessment of the clinical need, obtaining informed consent, use of a chaperone, and thorough documentation.

Conclusion: Telemedicine will play a pivotal role in the future of urological practice beyond this present pandemic. However, sensitive clinical examinations using such technology must be performed in appropriate settings and situations. Suitable training, enhanced documentation, communication, and observing information governance guidance will aid in avoiding clinical and ethical pitfalls.

Keywords: telemedicine, sensitive examination, remote examination, urology, COVID-19

\section{Introduction}

The World Health Organisation (WHO) declared the Coronavirus disease 2019 (COVID-19) a public health emergency on the 11th of March 2020, and the United Kingdom (UK) was one of the most-affected countries in Europe with over 91,000 deaths recorded in January 2021. ${ }^{1}$ The National Health Service (NHS) appropriately directed resources to prioritise and strengthen frontline service provision, including the redeployment of staff and the cancellation of routine outpatient clinics and elective surgeries. ${ }^{2}$ Globally, urological associations used a risk stratification approach to ensure care for non-oncological surgical procedures was kept to a minimum ${ }^{3}$ - Table 1 highlights the various recommendations.

One method of coping with the disruption to urological outpatient clinics was to utilise telemedicine software, which involves the "information technology for the
Correspondence: Chaitya Desai University Hospitals Birmingham NHS Foundation Trust, Birmingham, UK Tel +447493063410

Email chaitya.desai@nhs.net 
Table I Recommendations for Prioritisation of NonOncological Urological Procedures During the COVID-19 Pandemic as Issued by the British Association of Urological Surgeons (BAUS), ${ }^{4-8}$ European Association of Urology (EAU), ${ }^{9}$ and Urological Society of Australia and New Zealand (USANZ). ${ }^{10}$ American College of Surgeons (ACS) Guidelines are Not Included as They Did Not Reference Specific Procedures

\begin{tabular}{|c|c|c|c|}
\hline & $\begin{array}{l}\text { BAUS } \\
\text { Guidance } \\
\text { (Stages) }\end{array}$ & $\begin{array}{l}\text { EAU } \\
\text { Guidance } \\
\text { (Priorities) }\end{array}$ & $\begin{array}{l}\text { USANZ } \\
\text { Guidance } \\
\text { (Urgent } \\
\text { Interventions) }\end{array}$ \\
\hline Urodynamics & I & Low & Defer \\
\hline BPH surgery & 1 & Low & Defer \\
\hline $\begin{array}{l}\text { Other benign } \\
\text { conditions (ie } \\
\text { varicocele, } \\
\text { hydrocele) }\end{array}$ & I & Low & Defer \\
\hline Cystoscopy & I & $\begin{array}{l}\text {-High } \\
\text { (macroscopic } \\
\text { haematuria) } \\
\text {-Low- } \\
\text { Intermediate } \\
\text { (F/U without } \\
\text { haematuria) }\end{array}$ & $\begin{array}{l}\text {-Follow-up for } \\
\text { high-risk } \\
\text {-Diagnostic for } \\
\text { abnormal } \\
\text { radiology or } \\
\text { cytology }\end{array}$ \\
\hline $\begin{array}{l}\text { Removal of } \\
\text { a double-J stent }\end{array}$ & $\begin{array}{l}\text { Delay if } \\
\text { possible }\end{array}$ & $\begin{array}{l}\text { Low- } \\
\text { Intermediate } \\
\text { (based on } \\
\text { symptoms) }\end{array}$ & Defer \\
\hline $\begin{array}{l}\text { Calculi } \\
\text { management } \\
\text { (without } \\
\text { infection) }\end{array}$ & $\begin{array}{l}-I \text { (elective } \\
\text { URS and } \\
\text { PCNL) } \\
-3 \text { (URS } \\
\text { with stent } \\
\text { or ureteric } \\
\text { calculi) }\end{array}$ & $\begin{array}{l}\text { Low-High } \\
\text { (based on } \\
\text { symptoms) }\end{array}$ & $\begin{array}{l}\text { Only if } \\
\text { symptomatic }\end{array}$ \\
\hline
\end{tabular}

Notes: BAUS stages: I = first cancellation, 3 = last to be cancelled.

Abbreviations: F/U, follow-up; URS, ureteroscopy; PCNL, percutaneous nephrolithotomy.

purpose of providing remote health assessments and therapeutic interventions." 4 With the "COVID catalyst," more centers globally started implementing its use in some form, and $80.9 \%$ of urologists surveyed in a global study advocated for its continued use for future practice. ${ }^{5}$ For instance, a center in the United Kingdom found that the use of telemedicine for real-time remote consultations combined with clinical risk stratification enabled $86 \%$ of oncological and $91 \%$ of benign urological outpatient activities to be carried out. ${ }^{6}$ There are various means of utilising telemedicine to aid patients - Table 2 highlights some examples. ${ }^{7}$

Telemedicine offers several key benefits for patients with urological presentations.

Firstly, it allowed increased access to care for certain "at-risk" groups in the populations: ie those who are immunocompromised. ${ }^{8}$ A recent report from a German urological referral centre evaluated 400 patients scheduled for a face-to-face consultation, and their data showed approximately $95 \%$ of the patients were at increased risk for a severe outcome of COVID-19 and that $85 \%$ of them would have favoured a remote consultation. ${ }^{7}$ Furthermore, studies reviewing the efficacy of telemedicine for urological presentations specifically have shown positive results for managing malignancy such as prostate cancer, as well as benign disease such as urinary incontinence, pelvic organ prolapse, uncomplicated urinary stones, and uncomplicated urinary tract infections via remote consultations and a store-and-forward approach. ${ }^{8-10}$ Importantly, telemedicine can also be leveraged to reduce health disparities among underserved populations. For instance, it can provide access to healthcare for patients in rural areas. ${ }^{11}$

The telemedicine approach to consultations is pragmatic; however, it can become more difficult when a physical examination is required - particularly for urological presentations, where the examination may involve the patient's genital anatomy. Clinical sensitive examination, defined by the General Medical Council (GMC) as that involving digital rectal, vaginal, and genitalia, is a vital component in assessing many urological presentations. Although accomplishing this remotely via video link

Table 2 Examples of Telemedicine Approaches

\begin{tabular}{|l|l|}
\hline $\begin{array}{l}\text { Types of } \\
\text { Aplemedicine }\end{array}$ & Definition \\
\hline Real-time video visits & $\begin{array}{l}\text { Live video link between clinician and } \\
\text { patient to address a clinical presentation }\end{array}$ \\
\hline $\begin{array}{l}\text { Store-and-forward } \\
\text { (asynchronous transfer) }\end{array}$ & $\begin{array}{l}\text { Patients share data, ie images or videos, } \\
\text { to clinicians who review and treat } \\
\text { outside of real-time. }\end{array}$ \\
\hline Remote surveillance & $\begin{array}{l}\text { Patient's health and medical data is sent } \\
\text { in real-time for monitoring. }\end{array}$ \\
\hline Mobile health & $\begin{array}{l}\text { Use of any mobile communications } \\
\text { device as well as software applications to } \\
\text { support healthcare. }\end{array}$ \\
\hline
\end{tabular}


is impossible, there is the option for the patient to allow the clinician to view self-examination.

At present, remote sensitive examinations pose an unfamiliar environment for urologists. There has been no guidance from BAUS, EAU, USANZ, or the American Urological Association with relation to conducting remote sensitive clinical examinations. The aim of this article is to review the guidance provided by various other medical bodies such as the GMC regarding remote examinations and apply this guidance to sensitive urological complaints.

\section{Materials and Methods}

A literature review was performed using PubMed, SCOPUS, Google Scholar, and Research Gate in the first week of March 2021, to identify all recently published papers, studies, and guidance articles related to urological telemedicine. Our search strategy combined the only three Medical Subject Heading (MeSH) terms directly related to our topic "telemedicine," "guidance," and "sensitive examination" with the MeSH term "urologic diseases/therapy" and the keyword "urology." We limited our search to articles published in the last 5 years and those that were written in English. We then augmented the formal literature search by performing manual search engine queries to find articles in the press, presentations, and unpublished abstracts related to urological telemedicine and general regulatory and reimbursement issues.

\section{Review of Literature and Discussion Clinical Need}

Prior to initiating any sensitive examination, whether inperson or remote, a urologist must assess the clinical need. This was emphasised by recent GMC guidance, which states that requisite for such an examination must include "providing care" or "reaching a diagnosis." 12 The evaluation of clinical need is left to the clinician's discretion and the ambiguity of this guidance allows each patient to be evaluated on a case-by-case basis. The Australian Health Practitioner Regulation Agency (AHPRA) has advised clinicians to consider whether an additional "direct physical examination" will be necessary following the remote sensitive examination. ${ }^{13}$ In such cases, the role of the remote examination will be seen as a triaging tool rather than for diagnostic purposes. A study reviewing the storeand-forward approach as a triaging tool found that between two groups of urologists assessing the severity of haematuria in-person or via photographs sent to them, there was no difference in results for haematuria severity and need for further invasive treatments. ${ }^{14}$

There are also certain situations which exclude the provision of remote sensitive examinations. The Royal College of Surgeons England (RCSEng) toolkit released in response to the pandemic states that they should not be utilised when patients have "high-risk conditions" (predicted mortality of $\geq 10 \%$ using the appropriate specialty risk scoring mechanism), or an internal examination is required, or patients' mental health is unsuitable (eg dementia), or patients are unable to use remote technology to communicate in certain scenarios. ${ }^{15}$

The American Medical Association (AMA) recently released a telehealth playbook which also emphasises the importance of establishing a clinical need prior to commencing any form of remote examination. ${ }^{16}$ The guidance focusses on building patient confidence in the service by ensuring clear goals are set out from the start, for example focussing on "few chief complaints that providers agree will be easily resolved by a video visit."16 The AMA argue that once patients and clinicians become accustomed to having their medical complaints resolved through remote sensitive examinations, the system can then grow the program by continuously adding additional "chief" complaints to the triage. ${ }^{16}$ This concept of growing patient confidence has been evidenced by a German study which used telemedicine to discuss treatment options for patients with newly diagnosed prostate cancer. ${ }^{17}$ The online tutorial was piloted in 56 patients, and overall patient satisfaction with the tutorial was very high. Following this, the patients were evaluated three months in the future for any further issues related to their cancer, and patients had low decisional conflict (mean DCS 9.6, SD 11), and almost no decisional regret (mean DRS 6.4, SD 9.6), indicating a growing confidence in the telemedicine service. ${ }^{17}$

\section{Obtaining Informed Consent}

The GMC and Nursing and Midwifery Council (NMC) advise that to perform a remote sensitive assessment, the patient's clear informed consent is necessary. ${ }^{18}$ This is irrespective of whether the plan to conduct such an assessment was initiated by the patient or clinician. The need for informed consent also applies to storing any images or recording live-video assessments. Specifically, the Faculty of Sexual and Reproductive Healthcare (FSRH) state that the decision to store a sensitive image in the patient's clinical record must be "justifiable" and "transparent," 19 with the emphasis on only recording an 
assessment if this is what a clinician would do in a face-toface assessment.

In terms of specific guidance regarding the process of obtaining informed consent, the GMC gave an overview of key points which should be explained to the patient. ${ }^{20}$ Although not specifically for urologists, the guidelines can be adapted to convey that the patient should understand what information will be gained by the patient selfexamining or sending an image of the sensitive area, and this should be complemented by explaining to the patient why such an examination cannot be done in-person, ie due to COVID-19 restrictions. Patient should be aware of who is present for the remote sensitive assessment including any chaperones (remote or physical), and of anyone who may be indirectly involved in image/data transfer, ie admin staff, information technology staff involved in data transfer.

Another important component for understanding patient consent for remote sensitive examinations relies on adhering to existing case law in the respective country. In the UK, the GMC's new guidance on consent (principle $4)^{21}$ references "material risks," ie specific consideration must be given for the circumstances, concerns, personality, and idiosyncrasies of each individual patient. From a practical perspective, this means identifying key concerns from each individual patient and providing the option of a face-to-face assessment to all patients, with the appropriate pros and cons (ie delay in clinic appointments due to COVID-19 restrictions, entering secondary care facilities and viral transmission risks).

\section{Use of Chaperones}

The NHS and GMC have clear guidelines for having a chaperone present when undertaking face-to-face physical examinations for sensitive areas of a patient's body. ${ }^{22}$ These guidelines are summarised in Box $1 .{ }^{26}$ A chaperone has two key roles: to ensure the privacy and dignity of the patient and to protect the medical professional. In the context of remote sensitive assessments, the same guidelines apply, and this is irrespective of the gender of the clinician or patient. Prior to any remote sensitive examination and ideally at the time of booking, all patients should routinely be offered a chaperone. In a remote context, this chaperone will likely also be remotely located, and this feature is commonly available in most modern telemedicine software. As per the Royal College of Nursing, staff acting as chaperones must be given suitable training about the role and its requirements, with risk assessments and
Box I Summary of four key points from the GMC regarding chaperones for sensitive examination.

Point I: For any intimate examination, regardless of means conducted, the patient must be offered the option of having an impartial observer (a chaperone) present wherever possible. This applies regardless of the clinician and the patient being of the same gender.

Point 2: The chaperone should be a health professional that is:

a. 'sensitive and respect the patient's dignity and confidentiality'.

b. 'reassures the patient if they show signs of distress or discomfort'.

c. 'familiar with the procedures involved in a routine intimate

examination'.

d. 'stays for the whole examination and is able to see what the doctor is doing, if practical'.

e. 'is prepared to raise concerns if they are concerned about the doctor's behaviour or actions'.

Point 3: The patient's relative or friend cannot act as a chaperone as they are not 'impartial'.

Point 4: The clinician should record any discussion about chaperones and the outcome in the patient's medical record. If the patient does not want a chaperone, it should be recorded that the offer was made and declined, and the next step: i.e. if an examination at a later date was offered when a suitable chaperone available.

Notes: Data from General Medical Council. Intimate examinations and chaperones, 2013. Available from: https://www.gmc-uk.org///media/documents/maintainingboundaries-intimate-examinations-and-chaperones_pdf-5883523l.pdf?la=en\&hash= A6DCCA363F989E0304DI7FBC4ECB9C1060028385. ${ }^{26}$

a Disclosure and Barring Service (DBS) check as standard. ${ }^{18}$ Where a patient is offered but does not want a chaperone, it is important that the clinician has recorded that the offer was made and declined. Following this, the clinician should then reschedule the appointment within a reasonable timeframe. Thus, it is essential that a chaperone is present prior to commencing any remote sensitive examination via video-link.

Issues with technology are a common feature of providing medical care remotely. The Royal College of General Practitioners (RCGP) has highlighted that if a chaperone is not in the same room as the clinician (ie they are also working remotely), it is sensible to ensure that they are able to see and hear the consultation adequately prior to starting an examination. ${ }^{23}$ It may be helpful to have a plan with the chaperone on how to proceed in the event of problems arising. If a chaperone is requested but not available on the software system, then the urologist should not proceed with the remote examination and determine whether a subsequent appointment should be made, or a face-to-face examination would be more practical based on clinical and logistical urgency established from 
the patient history. The RCGP stress the importance of documenting such discussions and the decisions in the patient notes. $^{23}$

\section{Documentation}

The GMC is clear in their guidance towards documentation for remote sensitive assessments. ${ }^{24}$ As a clinician would in a face-to-face assessment, ensure thorough and contemporaneous written patient records are kept. The clinical need for sensitive examinations to be performed remotely must be clearly documented with justification. Importantly, the urologist must always document whether or not a chaperone was offered and declined or present at the consultation. If a chaperone was present, their identity, including designation and the extent of the assessment witnessed, must be documented. Furthermore, persons present for the remote sensitivity assessment include the urologist, patient, and any other parties present from the patient's side. If a sensitive image was sent, it is important to record who took the image, who sent it, and who has seen it from the clinical team. Discussions surrounding capacity, consent, and storage of images or videos must be recorded. The GMC stresses that each discussion should have clear justifications outlined. ${ }^{24}$ The age and mental state of the patient should also be recorded as it may be important to ensure a young person or vulnerable adult is kept safe when other clinicians are later involved in the care of the patient and review the sensitive images.

\section{Conclusion}

The "COVID-19 catalyst" has led to rapid adoption of telemedicine across urological services globally. ${ }^{25}$ The experience gained during this pandemic has opened up scenarios never previously considered by many centers, particularly with reference to the interaction between patient and clinician. The benefits of remote assessments extend beyond social distancing restrictions, ie easier and quicker access to clinicians, removing barriers represented by the logistics and costs of travelling to the hospital. However, the disadvantages of telemedicine cannot be entirely overlooked and as evidence shows, remote assessments are limited in effectiveness to a selected group of urological pathologies (ie managing prostate cancer, urinary incontinence, pelvic organ prolapse, uncomplicated urinary stones, and uncomplicated urinary tract infections). ${ }^{8}$ Ultimately, remote assessments should not undermine the importance of thorough clinical examination, clear communication, and patient safety. As aforementioned,

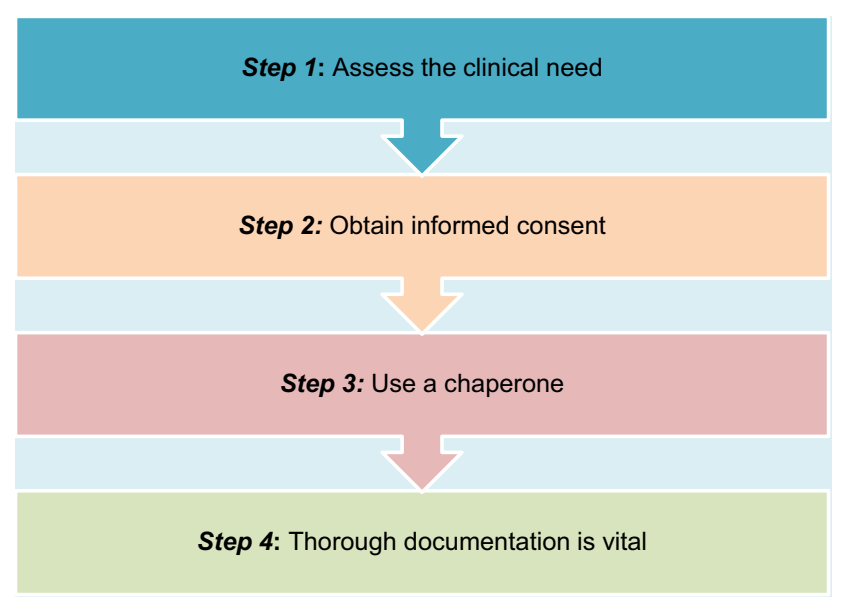

Figure I The four steps to consider prior to conducting a remote sensitive clinical examination.

all clinicians must be able to justify their decision to conduct a remote assessment in the patient's best interests.

In terms of remote assessment for performing sensitive clinical examinations, this article has highlighted key clinical and ethical considerations prior to embarking on this approach. These considerations are summarised in Figure 1. Telemedicine reduces unnecessary visits to medical facilities and is useful for reducing the risk of transmission in the current COVID-19 pandemic. Additional advantages may support the continued use of telemedicine when applicable, even beyond the COVID-19 pandemic.

\section{Informed Consent}

No patients were used in this study, so consent is not applicable.

\section{Author Contributions}

All authors made a significant contribution to the work reported, whether that is in the conception, study design, execution, acquisition of data, analysis, and interpretation, or in all these areas; took part in drafting, revising, or critically reviewing the article; gave final approval of the version to be published; have agreed on the journal to which the article has been submitted; and agree to be accountable for all aspects of the work.

\section{Funding}

This study received no funding.

\section{Disclosure}

The authors declare that they have no conflicts of interest. 


\section{References}

1. World Health Organization. Coronavirus disease (COVID-19) dashboard; 2021. Available from: https://covid19.who.int/. Accessed September 21, 2021.

2. Willan J, King AJ, Jeffery K, Bienz N. Challenges for NHS hospitals during covid-19 epidemic. Br Med J Publ Group. 2020:m1117. doi:10.1136/bmj.m1117

3. Weilongorska NL, Ekwobi CC. COVID-19: what are the challenges for NHS surgery? Curr Probl Surg. 2020;57:100856.

4. NHS. Data model and dictionary; 2020. Available from: https://data dictionary.nhs.uk/nhs_business_definitions/telemedicine.html\#: : text=COMMUNICATION\%20CONTACT $\% 20$ METHOD.Telemedicine $\% 20$ is $\% 20$ the $\% 20$ use $\% 20$ of $\% 20$ telecommunication $\%$ 20and\%20information\%20technology\%20for,mobile\%20phones $\% 2 \mathrm{C}$ $\% 20$ computers\%20and\%20tablets. Accessed September 21, 2021.

5. Dubin JM, Wyant WA, Balaji NC, et al. Telemedicine usage among urologists during the COVID-19 pandemic: cross-sectional study. J Med Internet Res. 2020;22(11):e21875. doi:10.2196/21875

6. Somani BK, Pietropaolo A, Coulter P, Smith J. Delivery of urological services (telemedicine and urgent surgery) during COVID-19 lockdown: experience and lessons learnt from a university hospital in United Kingdom. Scott Med J. 2020;65(4):109-111. doi:10.1177/ 0036933020951932

7. Boehm K, Ziewers S, Brandt MP, et al. Telemedicine online visits in urology during the COVID-19 pandemic-potential, risk factors, and patients' perspective. Eur Urol. 2020;78(1):16-20. doi:10.1016/j. eururo.2020.04.055

8. Novara G, Checcucci E, Crestani A, et al. Telehealth in urology: a systematic review of the literature. how much can telemedicine be useful during and after the COVID-19 pandemic? Eur Urol. 2020;78 (6):786-811. doi:10.1016/j.eururo.2020.06.025

9. Amparore D, Campi R, Checcucci E, et al. Forecasting the future of urology practice: a comprehensive review of the recommendations by international and European Associations on priority procedures during the COVID-19 pandemic. Eur Urol Focus. 2020;6(5):1032-1048. doi:10.1016/j.euf.2020.05.007

10. Checcucci E, De Luca S, Alessio P, et al. Implementing telemedicine for the management of benign urologic conditions: a single centre experience in Italy. World $J$ Urol. 2021;39(8):3109-3115. doi: 10.1007/s00345-020-03536-X

11. Chu S, Boxer R, Madison P, et al. Veterans affairs telemedicine: bringing urologic care to remote clinics. Urology. 2015;86 (2):255-261. doi:10.1016/j.urology.2015.04.038

12. GMC. Key principles for intimate clinical assessments undertaken remotely in response to COVID-19; 2020. Available from: https://www.gmc-uk. org/-/media/files/key_principles_for_intimate_clinical_assessments_under taken_remotely_in_response_to_covid19_v1-(1).pdf?la=en\&hash= 0A7816F6A8DA9240D7FCF5BDF28D5D98F1E7B194. Accessed September 21, 2021.
13. AHPRA. Telehealth guidance for practitioners; 2020. Available from: https://www.ahpra.gov.au/News/COVID-19/Workforce-resources /Telehealth-guidance-for-practitioners.aspx. Accessed September 21, 2021.

14. Sener TE, Butticè S, Sahin B, et al. WhatsApp use in the evaluation of hematuria. Int J Med Inform. 2018;111:17-23. doi:10.1016/j. ijmedinf.2017.12.011

15. RCSEng. Tool 4: virtual consultations; 2020. Available from: https:// www.rcseng.ac.uk/coronavirus/recovery-of-surgical-services/tool-4/. Accessed September 21, 2021.

16. AMA. Telehealth implementation playbook; 2020. Available from: https://www.ama-assn.org/system/files/2020-04/ama-telehealthimplementation-playbook.pdf. Accessed September 21, 2021.

17. Schaffert R, Dahinden U, Hess T, et al. [Evaluation of a prostate cancer E-health tutorial: development and testing of the website prostata-information.ch]. Urologe A. 2018;57(2):164-171. German. doi:10.1007/s00120-017-0552-8

18. RCN. Remote consultations guidance under COVID-19 restrictions; 2020. Available from: https://www.ren.org.uk/professionaldevelopment/publications/rcn-remote-consultations-guidance-undercovid-19-restrictions-pub-009256. Accessed September 21, 2021.

19. FSRH. Key principles for intimate clinical assessments; 2020. Available from: https://www.fsrh.org/standards-and-guidance/docu ments/fsrh-key-principles-for-intimate-clinical-assessments/. Accessed September 21, 2021

20. GMC. Remote consultations; 2020. Available from: https://www. gmc-uk.org/ethical-guidance/ethical-hub/remote-consultations. Accessed September 21, 2021

21. GMC. Decision making and consent; 2020. Available from: https:// www.gmc-uk.org/ethical-guidance/ethical-guidance-for-doctors/deci sion-making-and-consent. Accessed September 21, 2021.

22. GMC. Intimate examinations and chaperones; 2013. Available from: https://www.gmc-uk.org/-/media/documents/maintaining-boundariesintimate-examinations-and-chaperones_pdf-58835231.pdf?la= en\&hash=A6DCCA363F989E0304D17FBC4ECB9C1060028385. Accessed September 21, 2021

23. RCGP. Key principles for intimate clinical assessments undertaken remotely in response to COVID-19; 2020. Available from: https:// elearning.rcgp.org.uk/pluginfile.php/154305/mod_page/content/11/ Key\%20principles\%20for\%20intimate $\% 20$ clinical $\% 20$ assessments_ July\%202020.pdf

24. Key principles for intimate clinical assessments undertaken remotely in response to COVID-19; July, 2020.

25. Davis C, Novak M, Patel A, Davis C, Fitzwater R, Hale N. The COVID-19 catalyst: analysis of a tertiary academic institution's rapid assimilation of telemedicine. Urol Practice. 2020;7(4):247-251. doi:10.1097/UPJ.0000000000000155

26. General Medical Council. Intimate examinations and chaperones; 2013. Available from: https://www.gmc-uk.org/-/media/documents/maintainingboundaries-intimate-examinations-and-chaperones_pdf-58835231.pdf?la= en\&hash=A6DCCA363F989E0304D17FBC4ECB9C1060028385.

Accessed September 25, 2021.
Research and Reports in Urology

\section{Publish your work in this journal}

Research and Reports in Urology is an international, peer-reviewed, open access journal publishing original research, reports, editorials, reviews and commentaries on all aspects of adult and pediatric urology in the clinic and laboratory including the following topics: Pathology, pathophysiology of urological disease; Investigation and treatment of urological disease; Pharmacology of drugs used for the treatment of urological disease. The manuscript management system is completely online and includes a very quick and fair peer-review system, which is all easy to use. Visit http://www.dovepress.com/ testimonials.php to read real quotes from published authors. 